\title{
Female sex as independent risk factor for chronic pain following elective incisional hernia repair: registry-based, propensity score-matched comparison
}

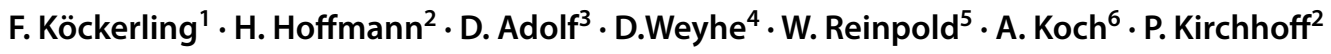

Received: 29 July 2019 / Accepted: 4 November 2019 / Published online: 27 November 2019

(c) The Author(s) 2019

\begin{abstract}
Introduction To date, little attention has been paid by surgical scientific studies to sex as a potential influence factor on the outcome. Therefore, there is a sex bias in the surgical literature. With an incidence of more than $20 \%$ after 3 years, incisional hernias are a common complication following abdominal surgical procedures. The proportion of women affected is around $50 \%$. There are very few references in the literature to the influence of sex on the outcome of elective incisional hernia repair. Materials and methods In all, 22,895 patients with elective incisional hernia repair from the Herniamed Registry were included in the study. The patients had undergone elective incisional hernia repair in a laparoscopic IPOM, open sublay, open IPOM, open onlay or suture technique. 1-year follow-up was available for all patients. Propensity score matching was performed for the 11,480 female (50.1\%) and 11,415 male (49.9\%) patients, creating 8138 pairs (82.0\%) within fixed surgical procedures.

Results For pain on exertion ( $11.7 \%$ vs $18.3 \%$; $p<0.001)$, pain at rest $(7.53 \%$ vs $11.1 \% ; p<0.001)$, and pain requiring treatment $(5.4 \%$ vs $9.1 \% ; p<0.001)$ highly significant disadvantages were identified for the female sex when comparing the different results within the matched pairs. That was also confirmed on comparing sex within the individual surgical procedures. No sex-specific differences were identified for the postoperative complications, complication-related reoperations or recurrences. Less favorable intraoperative complication results in the female sex were observed only for the onlay technique. Conclusions Female sex is an independent risk factor for chronic pain after elective incisional hernia repair.
\end{abstract}

Keywords Incisional hernia $\cdot$ Female sex $\cdot$ Chronic pain $\cdot$ Hernia registry $\cdot$ Postoperative complications $\cdot$ Recurrence

F. Köckerling

ferdinand.koeckerling@ vivantes.de

1 Department of Surgery and Center for Minimally Invasive Surgery, Academic Teaching Hospital of Charité Medical School, Vivantes Hospital, Neue Bergstrasse 6, 13585 Berlin, Germany

2 Center for Hernia Surgery and Proctology, St. Johanns-Vorstadt 44, 4056 Basel, Switzerland

3 StatConsult GmbH, Halberstädter Strasse 40 a, 39112 Magdeburg, Germany

4 Pius Hospital Oldenburg, Medical Campus of University of Oldenburg, University Hospital of Visceral Surgery, Georgstraße 12, 26121 Oldenburg, Germany

5 Department of Surgery, Wilhelmsburger Hospital Groß Sand, Academic Teaching Hospital of University Hamburg, Groß Sand 3, 21107 Hamburg, Germany

6 Hernia Center Cottbus, Gerhard-Hauptmann-Strasse 15, 03044 Cottbus, Germany

\section{Introduction}

To date, little attention has been paid by surgical scientific studies to sex as a potential influence factor on the outcome $[1,2]$. Therefore, there is sex bias in the surgical literature [1]. The Surgery Journal Editors Group has published a statement specifying that in the future sex should be considered as a biologic variable in all studies [3, 4].

With an incidence of up to $22.4 \%$ after three years, incisional hernias are a common complication following abdominal surgical procedures [5-7].

In registry studies there is essentially no difference between the proportion of men and women in the total collective of incisional hernias, with each accounting for $50 \%$ [8-11].

There are very few references in the literature to the influence of sex on the outcome of elective incisional hernia repair. Data from healthcare cost and utilization 
project—nationwide inpatient sample-on 59,993 elective ventral- and incisional hernia-repairs showed higher mortality for the male sex [12]. A prospective study of 887 ventraland incisional hernia-patients from the International Hernia Mesh Registry revealed an increased risk of chronic pain for the female gender [13].

The following study of data from the Herniamed Hernia Registry $[14,15]$ aimed to show differences in the outcome of male vs female patients following elective incisional hernia repair.

\section{Materials and methods}

The Herniamed quality assurance study is a multicenter, internet-based hernia registry $[14,15]$ into which 712 participating hospitals and surgeons (Herniamed Study Group) in Germany, Austria, and Switzerland (status: February 1, 2019) have entered data prospectively on their patients who had undergone routine hernia surgery [16]. All patients signed an informed consent agreeing to participate [16]. As part of the information provided to patients regarding participation in the herniamed hernia registry and signing the informed consent declaration all patients are informed that the treating hospital or medical practice would like to be informed about any problem occurring after the operation and that the patient has the opportunity to attend clinical examination [17].

All postoperative complications occurring up to 30 days after surgery were recorded [16]. At 1-year follow-up, postoperative complications were once again reviewed when the general practitioner and patient completed a questionnaire [16]. At 1-year follow-up, the general practitioner and the patient were also asked about any recurrences, pain at rest, pain on exertion, and chronic pain requiring treatment [16]. The relevance of patient reported outcomes after incisional hernia repair was demonstrated [18].

The present retrospective analysis of prospective data compares the perioperative and one-year follow-up data of female and male patients who underwent elective incisional hernia repair between September 1, 2009 and January 1,2018 . The surgical procedures included in the analysis were the laparoscopic-intraperitoneal onlay mesh (IPOM), open sublay, IPOM, and onlay techniques as well as opensuture repair. Inclusion criteria were a valid minimum age of 16 years, elective-incisional hernia repair, use of approved meshes on the market, and complete registry database entry in mandatory fields, including complete 1-year follow-up.

Physiomesh was excluded from this analysis because of its voluntary market withdrawal [19]. For enhanced comparability, recurrences were also excluded.
All statistical analyses were performed using the software SAS 9.4 (SAS Institute Inc., Cary, NC) and intentionally calculated to a full significance level of $5 \%$, i.e., they were not corrected with respect to multiple testing, and each $p \leq 0.05$ represents a significant result.

Propensity score matching was performed using greedy algorithm and a caliper of 0.1 standard deviations. The variables used for matching were as follows:

American Society of Anesthesiologists (ASA) status, age, body mass index (BMI, $\mathrm{kg} / \mathrm{m}^{2}$ ), preoperative pain, incisional hernia defect size $(\mathrm{W} 1 \leq 4 \mathrm{~cm}, \mathrm{~W} 2 \geqq 4-10 \mathrm{~cm}, \mathrm{~W} 3>10 \mathrm{~cm})$, and defect localization (medial, lateral, combined) according to the European Hernia Society classification [20], mesh size $\left(\mathrm{cm}^{2}\right)$, use of drain (yes vs no), risk factors (chronic obstructive pulmonary disease, diabetes mellitus, aortic aneurysm, immune suppression, cortisone medication, smoking, coagulopathy, anticoagulant, or antiplatelet medication), and operative procedure. The latter had to be identical within each of the pairs.

The balance of the matched sample was assessed using standardized differences (also given for the pre-matched sample), which should not exceed $10 \%(<0.1)$ after creating matched pairs. For pairwise comparison of matching parameters between female and male patients (to present the differences between the original pre-matched samples), $\chi^{2}$ test and $t$ tests (Satterthwaite) were performed for categorical and continuous variables, respectively. Mesh size had been log-transformed beforehand due to the strong deviation from the normal distribution.

Matched samples were then analyzed for perioperative and 1-year follow-up outcomes (intra- and postoperative complications, complication-related reoperations, pain at rest and on exertion, pain requiring treatment, and recurrences) via McNemar's test. The results obtained are presented as the non-diagonal elements of the $2 \times 2$ frequency table, the corresponding $\mathrm{p}$ values and the odds ratio (OR) estimates for matched samples with $95 \%$ confidence interval.

\section{Results}

In all, 22,895 patients were included in this retrospective analysis (Fig. 1). Of the 22,895 patients, 11,480 were women (50.1\%) and 11,415 men (49.9\%). Propensity score matching was performed for these 22,895 patients to obtain homogeneous comparison groups [21].

\section{Unadjusted analysis}

Comparison of the influence factors before matching showed significant differences between men and women (Table 1). For women suture techniques were used more often, they had fewer ASA classifications III/IV, more frequent preoperative 
Fig. 1 Flowchart of patient inclusion

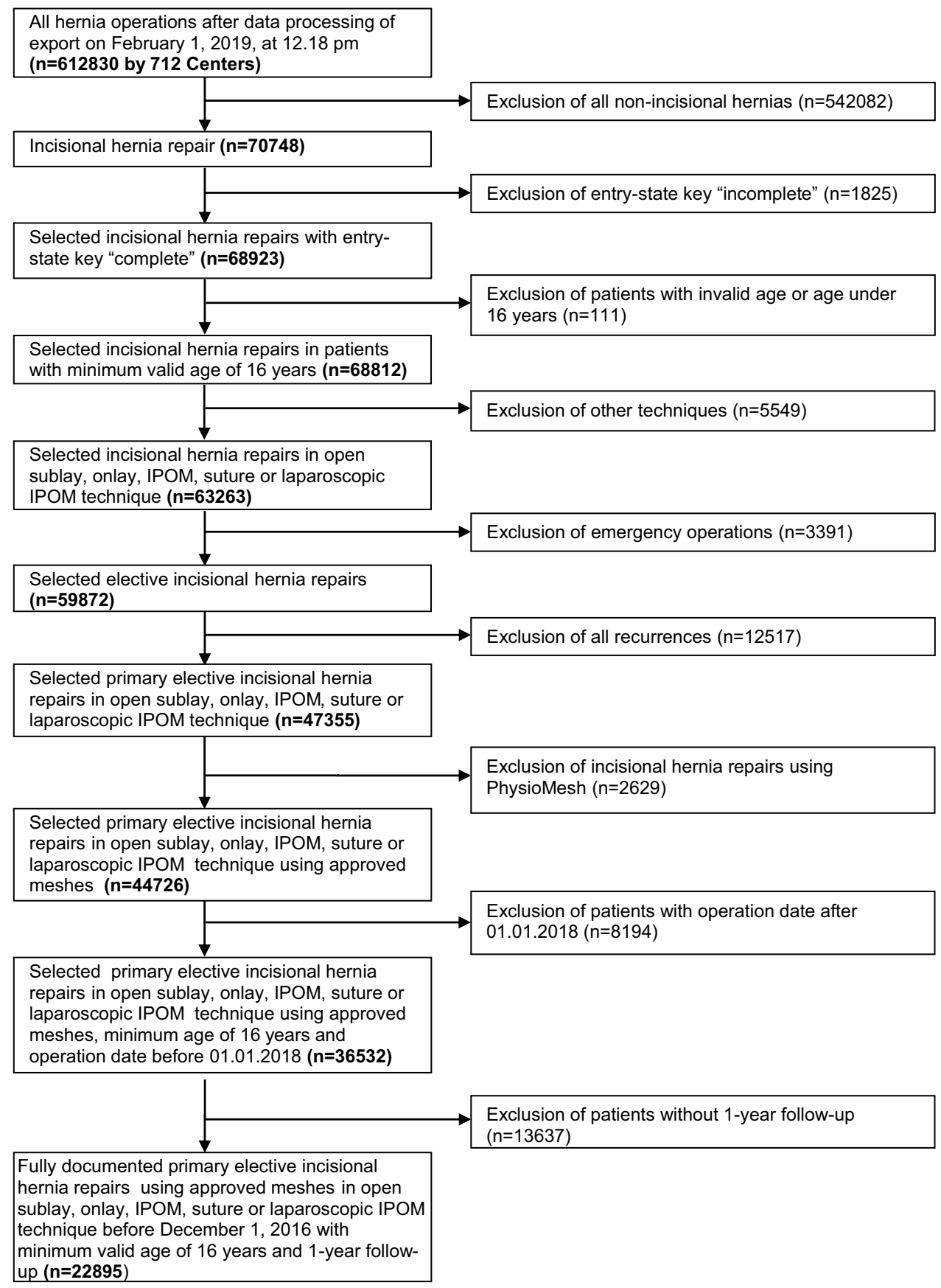

pain, fewer risk factors, higher BMI (male vs female: $27.7 \pm 4.8$ vs $29.6 \pm 6.6 ; p<0.001)$ and a smaller mesh had been used for them (male vs female: $241.1 \mathrm{~cm}^{2}$ [238.7; $243.6]$ vs $222.8 \mathrm{~cm}^{2}$ [220.5; 225.2]; $\left.p<0.001\right)$. No significant difference in age (male vs female: $62.8 \pm 12.6$ years vs $63.2 \pm 14.2$ years; $p=0.069$ ) or drain placement (male vs female: $55.9 \%$ vs $53.97 \%$; $p=0.091$ ) was identified between men and women.

\section{Matched pairs analysis}

Propensity score matching was performed using greedy algorithm and a permitted caliper width of 0.1 standard deviations for the 11,415 male and the 11,980 female patients. Matching was performed for $n=8138(82.0 \%)$ patients.

Figure 2 shows the standard differences between the matching variables both before (original sample) and after (matched sample) matching. 
Table 1 Patient and procedure related influencing factors on the outcome

\begin{tabular}{|c|c|c|c|c|c|}
\hline & \multicolumn{4}{|l|}{ Sex } & \multirow[t]{3}{*}{$p$} \\
\hline & \multicolumn{2}{|l|}{ Male } & \multicolumn{2}{|l|}{ Female } & \\
\hline & $n$ & $\%$ & $n$ & $\%$ & \\
\hline \multicolumn{6}{|l|}{ Procedure } \\
\hline Laparoscopic-POM & 3139 & 27.50 & 3222 & 28.07 & \multirow[t]{5}{*}{$<0.001$} \\
\hline Open suture & 1105 & 9.68 & 1557 & 13.56 & \\
\hline Open IPOM & 1692 & 14.82 & 1504 & 13.10 & \\
\hline Open Onlay & 622 & 5.45 & 676 & 5.89 & \\
\hline Open Sublay & 4857 & 42.55 & 4521 & 39.38 & \\
\hline \multicolumn{6}{|l|}{ ASA-score } \\
\hline I & 1267 & 11.10 & 1336 & 11.64 & \multirow[t]{3}{*}{$<0.00$} \\
\hline II & 6333 & 55.48 & 6637 & 57.81 & \\
\hline III/IV & 3815 & 33.42 & 3507 & 30.55 & \\
\hline \multicolumn{6}{|c|}{ EHS-classification (width) } \\
\hline $\mathrm{W} 1(<4 \mathrm{~cm})$ & 4132 & 36.20 & 4483 & 39.05 & \multirow[t]{3}{*}{$<0.00$} \\
\hline $\mathrm{W} 2(>=4-10 \mathrm{~cm})$ & 5245 & 45.95 & 5274 & 45.94 & \\
\hline $\mathrm{W} 3(>10 \mathrm{~cm})$ & 2038 & 17.85 & 1723 & 15.01 & \\
\hline \multicolumn{6}{|c|}{ EHS-classification (defect localisation) } \\
\hline Lateral & 1855 & 16.25 & 2112 & 18.40 & \multirow[t]{3}{*}{$<.00$} \\
\hline Medial & 8589 & 75.24 & 8461 & 73.70 & \\
\hline Combined & 971 & 8.51 & 907 & 7.90 & \\
\hline \multicolumn{6}{|l|}{ Preoperative pain } \\
\hline Yes & 5827 & 51.05 & 7261 & 63.25 & \multirow[t]{3}{*}{$<.00$} \\
\hline No & 4615 & 40.43 & 3244 & 28.26 & \\
\hline Unknown & 973 & 8.52 & 975 & 8.49 & \\
\hline \multicolumn{6}{|l|}{ Drainage } \\
\hline Yes & 6288 & 55.09 & 6196 & 53.97 & \multirow[t]{2}{*}{0.091} \\
\hline No & 5127 & 44.91 & 5284 & 46.03 & \\
\hline \multicolumn{6}{|l|}{ Risk factors } \\
\hline \multicolumn{6}{|l|}{ Total } \\
\hline Yes & 5078 & 44.49 & 4304 & 37.49 & \multirow[t]{2}{*}{$<.001$} \\
\hline No & 6337 & 55.51 & 7176 & 62.51 & \\
\hline \multicolumn{6}{|l|}{ COPD } \\
\hline Yes & 1147 & 10.05 & 1199 & 10.44 & \multirow[t]{2}{*}{0.323} \\
\hline No & 10,268 & 89.95 & 10,281 & 89.56 & \\
\hline \multicolumn{6}{|l|}{ Diabetes } \\
\hline Yes & 1427 & 12.50 & 1565 & 13.63 & 0.011 \\
\hline No & 9988 & 87.50 & 9915 & 86.37 & \\
\hline Aortic aneurism & & & & & \\
\hline Yes & 306 & 2.68 & 64 & 0.56 & $<.001$ \\
\hline No & 11,109 & 97.32 & 11,416 & 99.44 & \\
\hline Immunosuppression & & & & & \\
\hline Yes & 216 & 1.89 & 190 & 1.66 & 0.174 \\
\hline No & 11,199 & 98.11 & 11,290 & 98.34 & \\
\hline Corticoids & & & & & \\
\hline Yes & 168 & 1.47 & 221 & 1.93 & 0.008 \\
\hline No & 11,247 & 98.53 & 11,259 & 98.07 & \\
\hline Smoking & & & & & \\
\hline Yes & 1628 & 14.26 & 1119 & 9.75 & $<.001$ \\
\hline
\end{tabular}

Table 1 (continued)

\begin{tabular}{|c|c|c|c|c|c|}
\hline & \multicolumn{4}{|l|}{ Sex } & \multirow[t]{3}{*}{$p$} \\
\hline & \multicolumn{2}{|l|}{ Male } & \multicolumn{2}{|l|}{ Female } & \\
\hline & $n$ & $\%$ & $n$ & $\%$ & \\
\hline No & 9787 & 85.74 & 10,361 & 90.25 & \\
\hline \multicolumn{6}{|c|}{ Coagulopathy } \\
\hline Yes & 289 & 2.53 & 186 & 1.62 & $<.001$ \\
\hline No & 11,126 & 97.47 & 11,294 & 98.38 & \\
\hline \multicolumn{6}{|c|}{ Antiplatelet medication } \\
\hline Yes & 1688 & 14.79 & 1041 & 9.07 & $<.001$ \\
\hline No & 9727 & 85.21 & 10,439 & 90.93 & \\
\hline \multicolumn{6}{|c|}{ Anticoagulation therapy } \\
\hline Yes & 410 & 3.59 & 302 & 2.63 & $<.001$ \\
\hline No & 11,005 & 96.41 & 11,178 & 97.37 & \\
\hline
\end{tabular}

That difference was well below $10 \%$ for all matching variables, attesting to a good balance between the variables included in the model.

Figure 3 and Table 2 give a summary of the sex-specific results for the various outcome parameters. A search for systematic differences in the results for male vs female patients was undertaken. A systematic difference was identified between the sex groups for the intraoperative complications and the pain rates at 1-year follow-up. For the intraoperative complications, in addition to concordant complication cases for four pairs $(0.05 \%)$, a significant deviation was identified in favor of the male patients $(1.6 \%$ vs $2.0 \%$; $p=0.040)$. Likewise, for pain at rest, affecting 65 pairs $(0.8 \%)$ in the case of both men and women, highly significant disadvantages were noted for women $(7.53 \%$ vs $11.1 \% ; p<0.001)$. The same was true for pain on exertion $(11.7 \%$ vs $18.3 \%$; $p<0.001$ for an additional 284 pairs (3.5\%) with concordant pain) and pain requiring treatment $(5.4 \%$ vs $9.1 \% ; p<0.001)$, with the latter pain occurring additionally in 39 pairs $(0.5 \%)$ in both cases. No significant differences were seen between men and women in the postoperative complications, complicationrelated reoperations, general postoperative complications or the recurrence rates.

\section{Matched pairs analysis of the different surgical procedures}

To identify more accurately the role of sex as an independent influence factor on the outcome of individual surgical procedures too, matched pairs analyses were performed additionally for these subgroups. To that effect, the outcomes for men versus women were compared for 3837 pairs with open-sublay repair, 2475 pairs with laparoscopic-IPOM repair, 535 pairs with open-onlay repair, and 1267 pairs with open-IPOM method. These analyses were omitted for open-suture repair since that applied to 
Fig. 2 Standard differences between the matching variables both before (original sample) and after matching (matched sample)

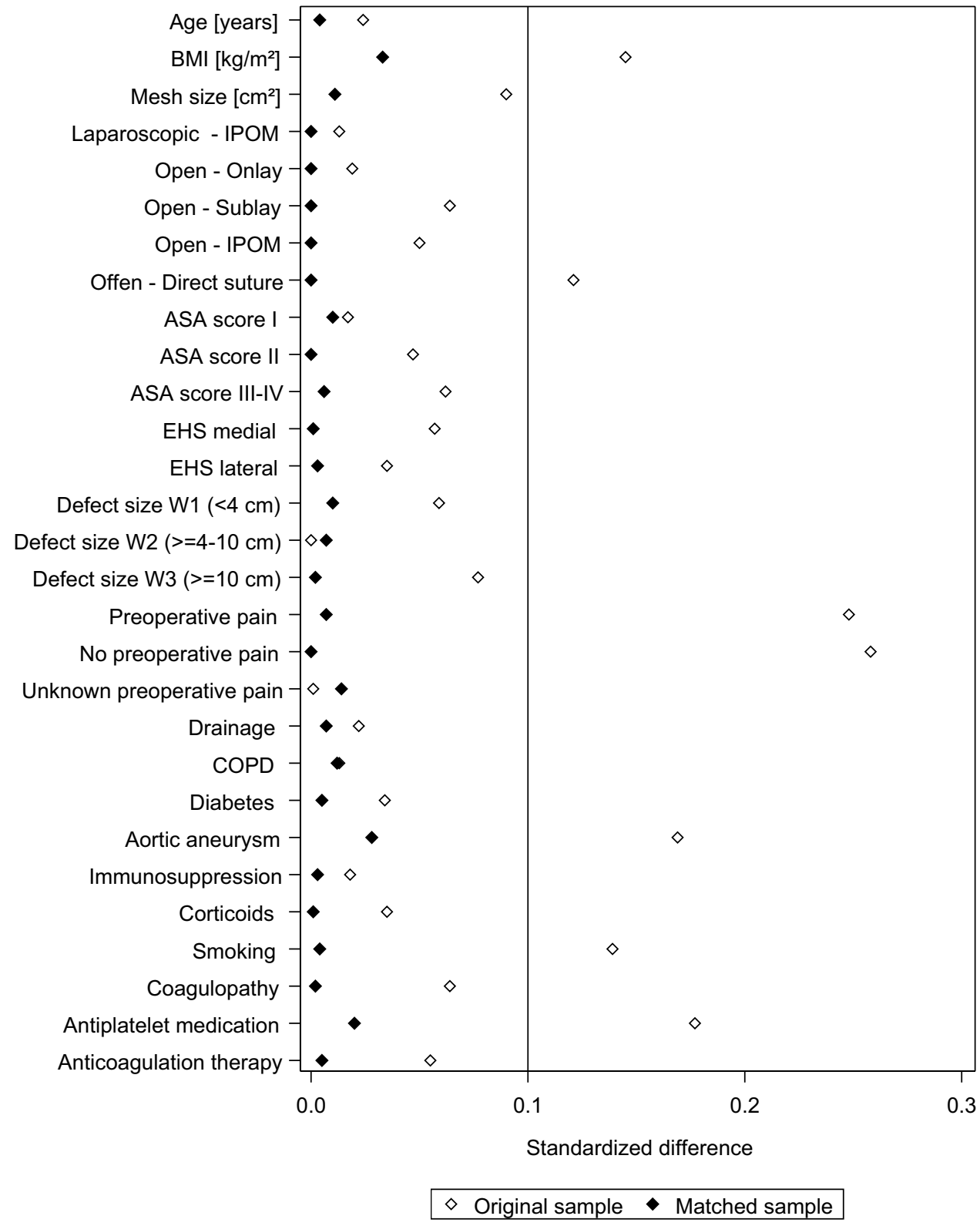

only 24 pairs. Below only the discordant matched-pairs outcomes are reported.

For the open-sublay repair highly significant differences $(p<0.001)$ to the disadvantage of women were identified for pain on exertion (men vs women: $12.1 \%$ vs $18.3 \%$ ), pain at rest (men vs women: $7.8 \%$ vs $11.2 \%$ ), and pain requiring treatment (men vs women $5.3 \%$ vs $9.2 \%$. For the intraoperative complications no significant difference (men vs women: $1.3 \%$ vs $1.5 \%$; $p=0.444$ ) was found (Table 3 ).

For the laparoscopic-IPOM repair comparable outcomes were noted. Likewise, for pain on exertion (men vs women: $11.4 \%$ vs $18.3 \%$ ), pain at rest (men vs women: $6.7 \%$ vs $10.8 \%$ ), and chronic pain requiring treatment (men vs women: $4.5 \%$ vs $8.9 \%$ ) highly significant differences $(p<0.001)$ were identified to the disadvantage of women. For laparoscopic-IPOM repair no difference was seen in the intraoperative complications (men vs women: $2.0 \%$ vs $2.4 \%$; $p=0.391$ ) (Table 4).

For the open-IPOM repair only for pain on exertion was a highly significant influence observed to the disadvantage of women (men vs women: $10.9 \%$ vs $17.5 \% ; p<0.001$ ). For pain at rest (men vs women: $8.5 \%$ vs $10.7 \% ; p=0.095$ ), and 
Fig 3 Results of matched pairs analysis of incisional hernia repair in female vs male patients

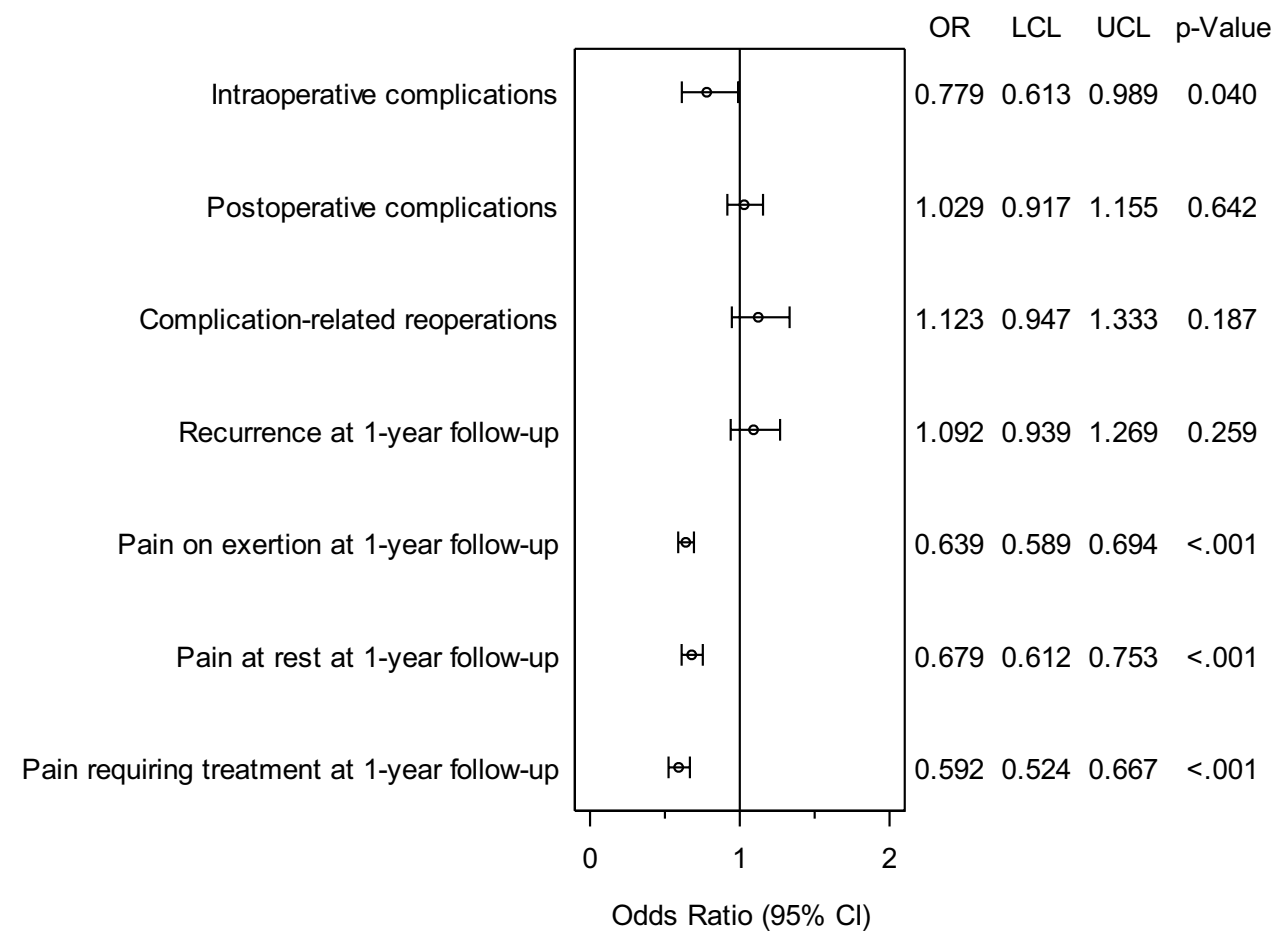

chronic pain requiring treatment (men vs women: $7.0 \%$ vs $9.1 \% ; p=0.068$ ) only a negative trend was identified for women. Likewise, for the open-IPOM repair no difference was found in the intraoperative complications between men and women (men vs women: $1.7 \%$ vs $2.1 \%$; $p=0.568$ ).

For the open-onlay repair female gender was found to have a highly significant negative influence on the outcome for pain on exertion (men vs women: $11.6 \%$ vs $19.8 \%$; $p<0.001$ ), a significantly negative influence for pain at rest (men vs women: $7.1 \%$ vs $13.1 \%$; $p=0.003$ ) and a negative trend towards chronic pain requiring treatment (men vs women: $6.4 \%$ vs $9.4 \% ; p=0.101$ ). For the open-onlay repair a disadvantage was also identified for women in the intraoperative complications (men vs women: $0.8 \%$ vs $3.0 \%$; $p=0.012$ ).

\section{Influence of BMI}

In a subgroup analyses of the matched pairs population comparing the subgroup of patients with and without reported pain in the 1-year follow-up no significant difference in the mean BMI was found in male $(29.27 \mathrm{vs} 29.15 \mathrm{~kg} /$ $\left.\mathrm{m}^{2} ; p=0.395\right)$ and female $\left(28.95 \mathrm{~kg} / \mathrm{m}^{2}\right.$ vs $29.01 \mathrm{~kg} / \mathrm{m}^{2}$; $p=0.710)$ patients.

\section{Sub-group of patients without follow-up}

To exclude selection bias of patients, an additional analysis of the sub-group of patients without 1-year follow-up was performed. With the exception of age with a mean difference of 2.4 years all other influencing factors and perioperative outcomes had a standardized difference below 0.1
Table 2 Results of matched pair analysis of incisional hernia repair in female vs male patients

\begin{tabular}{|c|c|c|c|c|c|c|}
\hline & \multicolumn{2}{|c|}{ Disadvantage } & \multirow[t]{2}{*}{$p$ value } & \multicolumn{3}{|c|}{ OR for matched samples } \\
\hline & Male & Female & & OR & Lower limit & Upper limit \\
\hline Intraoperative complications & 1.56 & 2.00 & 0.040 & 0.779 & 0.613 & 0.989 \\
\hline General complications & 3.19 & 3.61 & 0.161 & 0.884 & 0.746 & 1.049 \\
\hline Postoperative complications & 7.40 & 7.19 & 0.642 & 1.029 & 0.917 & 1.155 \\
\hline Complication-related reoperation & 3.59 & 3.19 & 0.187 & 1.123 & 0.947 & 1.333 \\
\hline Recurrence on 1-year-follow-up & 4.53 & 4.15 & 0.259 & 1.092 & 0.939 & 1.269 \\
\hline Pain on exertion on 1-year-follow-up & 11.67 & 18.26 & $<.001$ & 0.639 & 0.589 & 0.694 \\
\hline Pain in rest on 1-year-follow-up & 7.53 & 11.10 & $<.001$ & 0.679 & 0.612 & 0.753 \\
\hline $\begin{array}{l}\text { Chronic pain requiring treatment on1- } \\
\text { year-follow-up }\end{array}$ & 5.36 & 9.06 & $<.001$ & 0.592 & 0.524 & 0.667 \\
\hline
\end{tabular}


Table 3 Results of matched pair analysis of incisional hernia repair with sublay technique in female vs male patients

\begin{tabular}{|c|c|c|c|c|c|c|}
\hline & \multicolumn{2}{|c|}{ Disadvantages } & \multirow[t]{2}{*}{$p$ value } & \multicolumn{3}{|c|}{ OR for matched samples } \\
\hline & Male & Female & & OR & Lower limit & Upper limit \\
\hline Intraoperative complication & 0.75 & 2.99 & 0.012 & 0.250 & 0.061 & 0.775 \\
\hline General complication & 1.68 & 4.86 & 0.006 & 0.346 & 0.143 & 0.762 \\
\hline Postoperative complication & 9.35 & 9.35 & 1.000 & 1.000 & 0.662 & 1.511 \\
\hline Complication-related reoperation & 5.05 & 2.99 & 0.126 & 1.687 & 0.877 & 3.353 \\
\hline Recurrence on 1-year-follow-up & 4.67 & 6.54 & 0.245 & 0.714 & 0.410 & 1.228 \\
\hline Pain on exertion on 1-year-follow-up & 11.59 & 19.81 & $<0.001$ & 0.585 & 0.420 & 0.808 \\
\hline Pain in rest on 1-year-follow-up & 7.10 & 13.08 & 0.003 & 0.543 & 0.356 & 0.817 \\
\hline Pain requirement treatment on 1-year-follow-up & 6.36 & 9.35 & 0.101 & 0.680 & 0.426 & 1.072 \\
\hline
\end{tabular}

Table 4 Results of matched pair analysis of incisional hernia repair with laparoscopic IPOM technique in female vs male patients

\begin{tabular}{|c|c|c|c|c|c|c|}
\hline & \multicolumn{2}{|c|}{ Disadvantages } & \multirow[t]{2}{*}{$p$ value } & \multicolumn{3}{|c|}{ OR for matched samples } \\
\hline & Male & Female & & OR & Lower limit & Upper Limit \\
\hline Intraoperative complications & 2.02 & 2.42 & 0.391 & 0.833 & 0.561 & 1.233 \\
\hline General complications & 2.55 & 2.30 & 0.648 & 1.105 & 0.760 & 1.610 \\
\hline Postoperative complications & 3.19 & 3.72 & 0.359 & 0.859 & 0.628 & 1.173 \\
\hline Complication-related reoperation & 1.58 & 1.49 & 0.909 & 1.054 & 0.655 & 1.700 \\
\hline Recurrence on 1-year-follow-up & 4.00 & 4.08 & 0.944 & 0.980 & 0.735 & 1.306 \\
\hline Pain on exertion on 1-year-follow-up & 11.43 & 18.26 & $<0.001$ & 0.626 & 0.538 & 0.728 \\
\hline Pain in rest on 1-year-follow-up & 6.71 & 10.79 & $<0.001$ & 0.622 & 0.509 & 0.757 \\
\hline Pain requiring treatment on 1 -year-follow-up & 4.53 & 8.85 & $<0.001$ & 0.511 & 0.404 & 0.645 \\
\hline
\end{tabular}

compared to the patients with 1-year follow-up (Fig. 4). Therefore, both collectives are comparable which excludes selection bias. The higher age in the sub-group without follow-up demonstrates more difficulties in getting patient reported outcome information from the older patients.

\section{Discussion}

Since, to date, only very few studies in the surgical literature have considered sex as a biological variable, the Journal Editors Group has called upon surgical scientists to publish more sex-specific studies [1-4]. Whereas for inguinal hernia sex differences were only recently recompiled $[16,22]$, there is a paucity of publications on the influence of sex on the outcome after ventral- and incisional hernia-repair $[12,13]$. The large number of cases in registries are eminently suited to comparative studies of men vs women [23] since no patients are excluded and, at best, all other potential influence factors on the outcome are also taken into account.

For the 8138 pairs of opposite sex but with similar distribution of the other influence variables, in the present analysis highly significant differences were found in the rates of pain on exertion, pain at rest, and chronic pain requiring treatment at 1 -year follow-up to the disadvantage of the female gender. That finding was confirmed, too, in a subgroup analysis in which propensity score-matched pairs were also compared for the individual surgical procedures, and in which larger subsamples may yield higher power as a matter of course. For the most common surgical techniques, in particular, i.e., the open-sublay repair and laparoscopic-IPOM repair, female sex was found to have a highly significantly negative effect on chronic pain on exertion, pain at rest and pain requiring treatment. In a further subgroup analysis no influence of a higher BMI on the postoperative chronic pain rates could be found. This thus demonstrates that sex is an independent, unfavorable influence factor for chronic pain rates after incisional hernia repair.

In a series of 887 ventral hernia repairs Cox et al. [13], too, found female sex to be associated with a higher risk of chronic pain.

"Chronic or long-term pain following open-incisional hernia repair is poorly documented. Traditionally, studies of incisional hernia repair have focused only on short-term complications (infection, hematoma), major morbidity, hospital stay, and recurrence" [24]. 
Fig. 4 Standardized differences of the influencing factors and the perioperative outcomes between patient collectives with and without follow-up

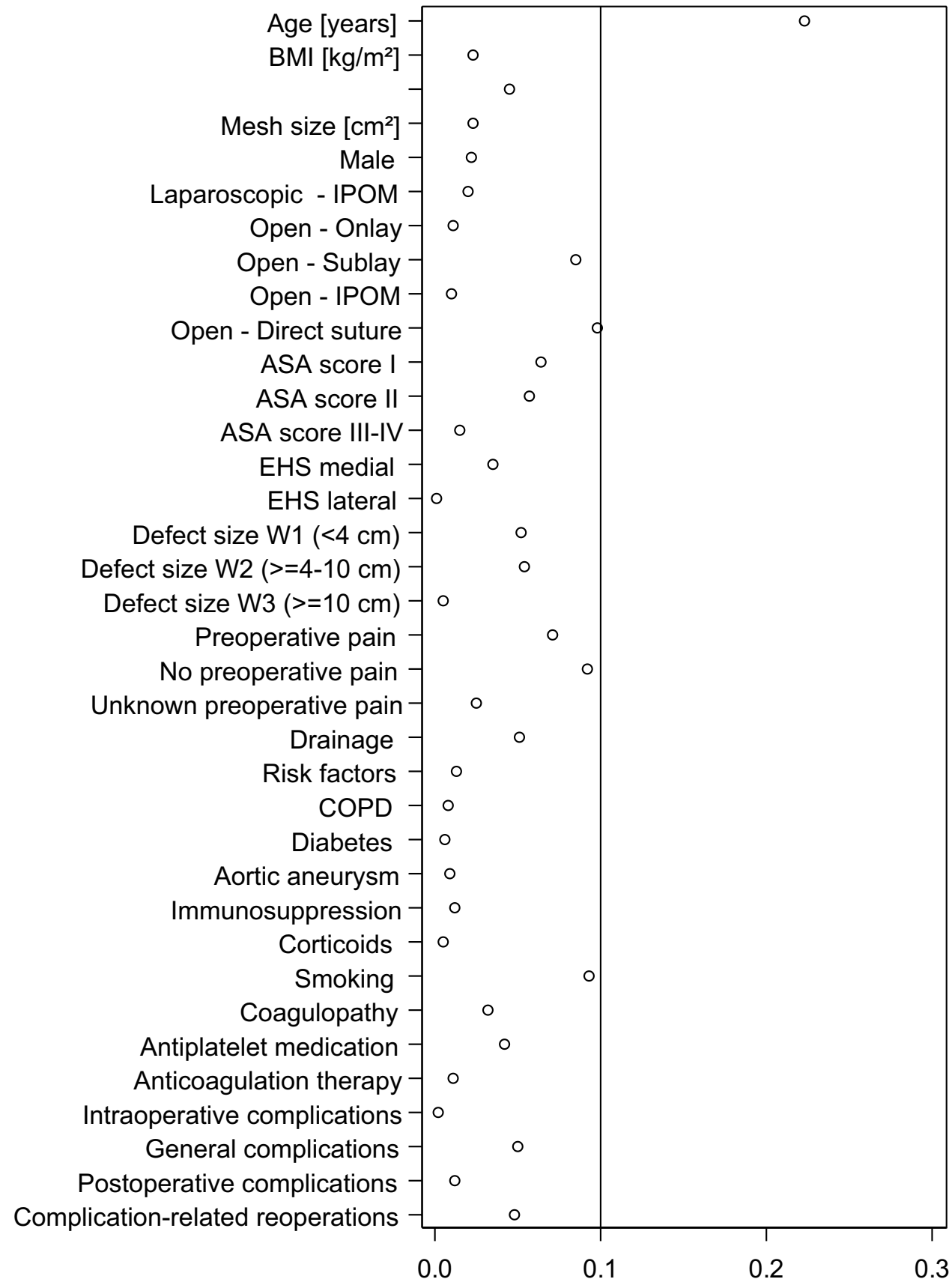

Standardized difference
For inguinal hernia a systematic review revealed that female gender had a significant influence on the rate of chronic inguinal pain after inguinal hernia repair [25].

In another review of chronic postoperative pain, in addition to preoperative pain, psychological factors (e.g., anxiety, depression, catastrophizing), younger age, surgical factors (e.g., open approach, length of operation $>3 \mathrm{~h}$ ), and intensity of pain in immediate postoperative period, female sex was also implicated in causation [26].
The analysis results of primary elective incisional hernia repair based on data from the Herniamed Hernia Registry thus confirm the findings in the literature indicating that female sex is an independent risk factor for chronic pain. That relationship can be statistically demonstrated, in particular, for the most commonly performed surgical procedures, i.e., laparoscopic-IPOM- and open-sublay repair. But for open IPOM and onlay repair, too, higher pain rates are identified for women with otherwise influence variables similar to men. 
"Men and women differ in their responses to pain, with increased pain sensitivity and risk of clinical pain commonly being observed among women" [27]. "After decades of assuming that pain works the same way in all sexes, scientists are finding that different biological pathways can produce pain" [28].

Female patients should therefore be informed about the higher risk of getting chronic postoperative pain in the preoperative counseling.

Matters are different as regards the intraoperative complications. Here, overall analysis reveals a slightly significant disadvantage for women. But that disadvantage can no longer be identified when comparing the individual surgical procedure subgroups for laparoscopic IPOM, open sublay, and open IPOM. Only for the onlay technique is a significant disadvantage observed for women. Hence, that disadvantage of female gender can be demonstrated only for the onlay technique. For the much more common surgical techniques, i.e., open sublay and IPOM as well as laparoscopic IPOM, no negative influence is seen.

Registry studies have a number of limitations. A relevant proportion of patients had to be excluded from analyses because no follow-up data were available. But the subgroup analysis does not show any suspicion of selection bias. Incorrect or missing data limit a registry [16]. Comparison with other registry or literature data is only possible to an extent due to the lack of publications. However, the findings reported here concord with the limited data available in the literature.

In conclusion, female sex is an independent risk factor for chronic pain after elective incisional hernia repair. That holds true for the surgical procedures laparoscopic IPOM, open sublay, open IPOM, and open onlay. Because of the small number of cases no conclusive statement can be made about open suture repair. No demonstrable disadvantage could be identified for female gender with regard to the perioperative complications, complication-related reoperations or recurrence rate.

\section{Compliance with ethical standards}

Conflict of interest Ferdinand Köckerling - Grants to fund the Herniamed Registry from Johson \& Johnson, Norderstedt, Karl Storz, Tuttlingen, pfm medical, Cologne, Dahlhausen, Cologne, B. Braun, Tuttlingen, Menke Med, Munich, Bard, Karlsruhe. H. Hoffmann, D. Adolf, D. Weyhe, W. Reinpold, A. Koch, P. Kirchhoff have no conflicts of interest to disclose.

Ethical approval As only cases of routine hernia surgery are documented in the Herniamed Registry, an ethical approval was not neccessary.

Human and animal rights This article does not contain any study with animals performed by any of the authors.
Informed consent All patients with routine hernia surgery documented in the Herniamed Registry have signed an informed consent declaration agreeing to participate.

Open Access This article is distributed under the terms of the Creative Commons Attribution 4.0 International License (http://creativeco mmons.org/licenses/by/4.0/), which permits unrestricted use, distribution, and reproduction in any medium, provided you give appropriate credit to the original author(s) and the source, provide a link to the Creative Commons license, and indicate if changes were made.

\section{References}

1. Mansukhani NA, Yoon DY, Teter KA, Stubbs VG, Helenowski IB, Woodruff TK, Kibbe MR (2016) Sex bias exists in human surgical clinical research. JAMA Surg 15:1022-1030. https://doi. org/10.1001/jamasurg.2016.2032

2. Howard R, Telem D (2019) Mandating sex as a biologic gender matters-variable in hernia research. Ann Surg. 270:10-11. https ://doi.org/10.1097/SLA.0000000000003323

3. Lillemoe KD (2018) Joint statement by the surgery journal editors group 2018. Ann Surg 267:991. https://doi.org/10.1097/SLA00 00000000002740

4. Kibbe MR (2018) Reporting of sex as a variable in research published in surgical journals. JAMA Surg 153:983. https://doi. org/10.1001/jamasurg.2018.2450

5. Bosanquet DC, Ansell J, Abdelrahman T, Cornish J, Harries R, Stimpson A et al (2015) Systematic review and meta-regression of factors affecting midline incisional hernia rates: analysis of 14,618 patients. PLoS ONE 10:e0138745. https://doi.org/10.1371/journ al.pone. 0138745

6. Fink C, Baumann P, Wente MN, Knebel P, Bruckner T, Ulrich A et al (2014) Incisional hernia rate 3 years after midline laparotomy. BJS 101:51-54. https://doi.org/10.1002/bjs.9364

7. Itatsu K, Yokoyama Y, Sugawara G, Kubota H, Tojima Y, Kurumiya $\mathrm{Y}$ et al (2014) Incidence of and risk factors for incisional hernia after abdominal surgery. BJS 101:1439-1447. https://doi. org/10.1002/bjs. 9600

8. Kokotovic D, Bisgaard T, Helgstrand F (2016) Long-term recurrence and complications associated with elective incisional hernia repair. JAMA 316(15):1575-1582. https://doi.org/10.1001/ jama.2016.15217

9. Köckerling F, Simon T, Adolf D, Köckerling D, Mayer F, Reinpold W, Weyhe D, Bittner R (2019) Laparoscopic IPOM versus open sublay technique for elective incisional hernia repair: a registry-based, propensity score-matched comparison of 9907 patients. Surg Endosc. 33:3361-3369. https://doi.org/10.1007/ s00464-018-06629-2

10. Kroese LF, Gillion JF, Jeekel J, Kleinrensink GJ, Lange JF, the Hernia-Club Members (2018) Primary and incisional ventral hernias are different in terms of patient characteristics and postoperative complications - a prospective cohort study of 4565 patients. Int J Surg 51:114-119

11. Kroese LF, Kleinrensink GJ, Lange JF, Gillion JF, and the Hernia-Club Members (2017) External validation of the European hernia society classification for postoperative complications after incisional hernia repair: a cohort study of 2191 patients. J Am Coll Surg 226:223-229. https://doi.org/10.1016/j.jamco 11surg.2017.11.018

12. Khorgami Z, Huy BY, Mushtaq N, Chow GS, Sclabas GM (2018) Predictors of mortality after elective ventral hernia repair: an analysis of national inpatient sample. Hernia 23:979985. https://doi.org/10.1007/s10029-018-1841-x 
13. Cox TC, Huntington CR, Blair LJ, Prasad T, Lincourt AE, Heiniford BT, Augenstein VA (2016) Predictive modeling for chronic pain after ventral hernia repair. Am J Surg 212:501510. https://doi.org/10.1016/j.amjsurg.2016.02.021

14. Stechemesser B, Jacob DA, Schug-Paß C, Köckerling F (2012) Herniamed: an internet-based registry for outcome research in hernia surgery. Hernia 16:269-276. https://doi.org/10.1007/ s10029-012-0908-3

15. Kyle-Leinhase I, Köckerling F, Jørgensen LN, Montgomery A, Gillion JF, Rodrigues JAP et al (2018) Comparison of hernia registries: the CORE project. Hernia. https://doi.org/10.1007/ s10029-017-1724-6

16. Köckerling F, Lorenz R, Hukauf M, Grau H, Jacob D, Fortelny $R$, Koch A (2019) Influencing factors on the outcome in female groin hernia repair a registry-based multivariable analysis of 15,601 patients. Ann Surg 270:1-9. https://doi.org/10.1097/ SLA.0000000000003271

17. Köckerling F, Bittner R, Kofler M, Mayer F, Adolf D, Kuthe A, Weyhe D (2019) Lichtenstein versus total extraperitoneal patch plasty versus transabdominal patch plasty technique for primary unilateral inguinal hernia repair. Ann Surg 269:351357. 10/1097/SLA.0000000000002541

18. Baucom RB, Ousley J, Feurer ID, Beveridge GB, Pierce RA, Holzman MD, Sharp KW, Poulose BK (2016) Patient reported outcomes after incisional hernia repair-establishing the ventral hernia recurrence inventory. Am J Surg 212:81-88. https://doi. org/10.1016/j.amjsurg.2015.06.007

19. Köckerling F, Simon T, Hukauf M, Hellinger A, Fortelny R, Reinpold W, Bittner R (2018) The importance of registries in the postmarketing surveillance of surgical meshes. Ann Surg 268:1097-1104. https://doi.org/10.10907/SLA000000000000 2326

20. Muysoms FE, Miserez M, Berrevoet F, Campanelli G, Champault GG, Chelala E, Dietz UA, Eker HH, El Nakadi I, Hauters
P, Hidalgo Pascual M, Hoeferlin A, Klinge U, Montgomery A, Simmermacher RKF, Simons MP, Smietanski M, Sommeling C, Tollens T, Vierendeels T, Kingsnorth A (2009) Classification of primary and incisional abdominal wall hernias. Hernia 13:407-414. https://doi.org/10.1007/s10029-009-0518-x

21. Lonjon G, Porcher R, Ergina P, Fouet M, Boutron I (2017) Potential pitfalls of reporting and bias in observational studies with propensity score analysis assessing a surgical procedure: a methodological systematic review. Ann Surg 265:901-909. https://doi.org/10.1097/SLA.0000000000001797

22. Köckerling F, Koch A, Lorenz R (2019) Groin hernias in women-a review of the literature. Front Surg 6:4. https://doi. org/10.3389/fsurg.2019.00004

23. Koch A, Edwards A, Haapaniemi S, Nordin P, Kald A (2005) Prospective evaluation of 6895 groin hernia repairs in women. Br J Surg 92:1553-1558. https://doi.org/10.1002/bjs.5156

24. Kurzer M, Kark A, Hussain ST (2010) Chronic pain after open mesh repair of incisional hernia. In: Schumpelick et al (eds) Hernia repair sequelae. Springer, Heidelberg

25. Reinpold W (2017) Risk factors of chronic pain after inguinal hernia repair: a systematic review. Innov Surg Sci 2:61-68. https ://doi.org/10.1515/iss-2017-0017

26. Corell D (2017) Chronic postoperative pain: recent findings in understanding and management. F1000 Res. https://doi. org/10.12688/f1000research.11101.1

27. Bartley EJ, Fllingim RB (2013) Sex differences in pain: a brief review of clinical and experimental findings. Br J Anast 111:5258. https://doi.org/10.1093/bja/aet127

28. Dance A (2019) The pain gap. Nature 567:448-550

Publisher's Note Springer Nature remains neutral with regard to jurisdictional claims in published maps and institutional affiliations. 